\section{SAPONIFY HANDMADE SOAP: EKONOMI KREATIF PendukUng LITERASI FINANSIAL SISWA SMK}

Rina Oktaviyanthi', Mohammad
Kamil Husain' ${ }^{1}$ Hamdan'

1) Universitas Serang Raya

\begin{abstract}
Abstraksi
Fokus kegiatan pengabdian ini yaitu pelatihan usaha dan tata kelola keuangan untuk memahamkan dan meningkatkan literasi finansial siswa SMK melalui pembuatan sabun rumah tangga. Metode apprenticeship digunakan untuk mencapai tujuan dengan tahapan kegiatan terdiri atas modeling, coaching dan scaffolding diimplementasikan pada 10 siswa SMKN 5 dan 10 siswa SMKS 17 Kota Serang sebagai mitra kegiatan. rata-rata pemahaman siswa dalam kegiatan apprenticeship mengenai peluang usaha dan tata kelola keuangan untuk memahamkan dan meningkatkan literasi finansial siswa SMK cukup baik yaitu $62,5 \%$. Nilai tersebut memberikan indikasi positif bahwa kegiatan pengabdian ini memberikan dampak yang baik sebagai permulaan untuk membangun motivasi dalam memulai atau membuka usaha. Hasil kegiatan ini menjadi bahan refleksi dan pertimbangan tim pengabdian Universitas Serang Raya dan pihak sekolah untuk bekerjasama menyelenggarakan kegiatan lanjutan dan berkesinambungan.
\end{abstract}

Keywords: apprenticeship, literasi finansial, sabun rumah tangga, saponify handmade soap, siswa SMK

\begin{abstract}
The focus of the community learning service program was a business training and financial management to understand and improve the financial literacy of vocational students through the production of household soap. The apprenticeship method was used to achieve the goal with the stages of the activity consist of the modeling, coaching and scaffolding implemented in each 10 students in SMKN 5 and SMKS 17 Kota Serang as the participant. The average of the students' understanding in apprenticeship activities regarding the business opportunities and financial literacy of vocational students is quite good at $62,5 \%$. The value provides a positive indication to the community learning service program. It has a good impact as a beginning to build motivation in starting a business. The results of this activity were a reflection and consideration of the Universitas Serang Raya as an organizer team and the school to work together to carry out follow-up and continuous activities
\end{abstract}

Keywords: apprenticeship, financial literacy, household soap, saponify handmade soap, vocational student

\section{PENDAHULUAN \\ Latar Belakang}

Sekolah Menengah Kejuruan (SMK) oleh sebagian kalangan, tidak terkecuali di Kota Serang Provinsi Banten, masih dipercaya sebagai tempat mempersiapkan diri generasi muda untuk menjadi ahli dan terampil menghadapi tuntutan dan tantangan perubahan zaman. Seperti yang tercantum dalam Undang-Undang Nomor 20 Tahun 2003 mengenai Sistem Pendidikan Nasional pasal 15 bahwa pendidikan kejuruan adalah jenjang sekolah menengah yang mempersiapkan peserta didik dalam bidang tertentu (Departemen Pendidikan Nasional Republik Indonesia, 2006). Salah satu tujuan khusus penyelenggaraan SMK menurut Pendidikan Menengah Kejuruan (2008) adalah membentuk siswa menjadi pribadi produktif, individu yang mandiri dan dapat bekerja independen. Jones (2018) menggarisbawahi bahwa tujuan khusus tersebut perlu diwujudkan sebagai langkah pendukung gerakan generasi muda yang kreatif, inovatif dan mengarah kepada kebebasan finansial di usia muda.

Lebih jauh Idialu (2013) menuturkan bahwa pribadi produktif yang menjadi arahan program sekolah kejuruan pada peserta didiknya berhubungan dengan segala kegiatan yang menghasilkan nilai tambah pada sesuatu. Sehingga diharapkan peserta didik dari SMK mampu melihat peluang dari setiap situasi dan kondisi untuk menciptakan sesuatu yang memiliki nilai tambah. Sementara Kersh dan Juul (2015) menyampaikan 
bahwa individu mandiri yang menjadi salah satu fokus lulusan SMK berkaitan dengan sikap siswa yang mampu mengambil keputusan berdasarkan pengetahuan dan pemahaman diri dan tidak bergantung pada orang lain. Tujuan sikap tersebut adalah agar siswa dapat bertahan di setiap tahapan kehidupan. Selanjutnya, Toth (2012) mengulas tentang independensi dalam bekerja sebagai suatu posisi yang mengarah pada profesionalitas dan melakukan kegiatan sesuai standar. Dengan demikian, siswa SMK dapat bertindak dan berperan sesuai tanggungjawab dan kapasitasnya.

Faktanya di lapangan, khususnya di Kota Serang Provinsi Banten, dalam kurun waktu dua tahun, yakni Agustus tahun 2017 dan Agustus tahun 2018, diketahui Tingkat Pengangguran Terbuka (TPT) dari lulusan SMK selalu menempati posisi tertinggi dibandingkan jenjang pendidikan lain. Badan Pusat Statistik Provinsi Banten (2017) dan Kantor Perwakilan Bank Indonesia Provinsi Banten (2018) mencatat pada Agustus tahun 2017 TPT Iulusan SMK adalah 14,25\%, sementara pada Agustus tahun 2018 TPT Iulusan SMK adalah 10,69\%. Meskipun secara persentase angka terjadi penurunan TPT, namun faktanya adalah TPT lulusan SMK selalu berada di posisi tertinggi. Kantor Perwakilan Bank Indonesia Provinsi Banten (2018) menyatakan TPT tersebut mengindikasikan adanya ketidaksesuaian antara lapangan pekerjaan dengan ketersediaan tenaga kerja yang disebabkan kebutuhan kompetensi yang tidak dapat dipenuhi. Data tersebut bertolak belakang dengan kondisi yang diharapkan pada lulusan SMK yang mandiri, kreatif dan bebas finansial di usia muda.

Xu dan Zia (2012) menyebutkan salah satu upaya menjadikan individu khususnya generasi muda melek finansial yaitu melalui program ekonomi kreatif yang dapat berdampak pada kemandirian dan bebas finansial. Berdasarkan hasil wawancara pada beberapa SMK di Kota Serang diketahui bahwa kegiatan untuk mengembangkan kemampuan kreatifitas siswa dalam bidang ekonomi kreatif maupun finansial sangat terbatas. Hal tersebut tidak hanya dilatarbelakangi oleh masalah dukungan dana melainkan atensi dan urgensi pihak sekolah yang masih rendah dengan argumentasi tidak berhubungan dengan kurikulum. Oleh karena itu, perlu adanya dukungan pihak lain yang dapat menjadi penjembatan terlaksananya program pengayaan tersebut. Inisiasi program ekonomi kreatif pada siswa SMK telah dilakukan oleh sejumlah pihak, termasuk tim dosen Universitas Serang Raya, salah satunya yakni mengembangkan livelihood skills siswa SMK melalui pelatihan pembuatan sabun rumah tangga (Oktaviyanthi, Djamal dan Agus, 2015).
Dengan memperhatikan dan mempertimbangkan ketidakidealan kondisi di lapangan dan karakteristik masalah yang dihadapi siswa SMK sebagai mitra, maka tim pelaksana program pengabdian Universitas Serang Raya beserta pihak sekolah memandang perlu untuk diselenggarakannya suatu kegiatan yang melibatkan siswa SMK yang berpotensi memahamkan dan meningkatkan literasi finansial melalui ekonomi kreatif pembuatan sabun rumah tangga.

\section{Rumusan Masalah}

Rumusan masalah yang menjadi fokus kegiatan pengabdian ini adalah bagaimana pelatihan usaha dan tata kelola keuangan untuk memahamkan dan meningkatkan literasi finansial siswa SMK melalui pembuatan sabun rumah tangga?

\section{Tujuan}

Fokus kegiatan pengabdian ini yaitu pelatihan usaha dan tata kelola keuangan untuk memahamkan dan meningkatkan literasi finansial siswa SMK melalui pembuatan sabun rumah tangga.

\section{Metodologi}

Untuk mencapai tujuan kegiatan pengabdian, metode apprenticeship yang tahapannya terdiri atas modeling, coaching dan scaffolding diimplementasikan pada 10 siswa SMKN 5 dan 10 siswa SMKS 17 Kota Serang sebagai mitra kegiatan. Apprenticeship atau yang lebih dikenal dengan pemagangan merupakan metode pembelajaran masa lalu dimana pembelajar memperoleh kemahiran mengenai sesuatu melalui proses kerja langsung bersama ahlinya secara bertahap (Collins, Brown dan Holum, 1991; Cave, 2010). Metode magang, menurut Horn (2014) adalah upaya yang cukup efektif dalam menjadikan pembelajar ahli pada suatu bidang yang menjadi konsentrasinya. Adapun langkahlangkah kegiatan pengabdian dengan metode apprenticeship ini yaitu:

1. Modeling, siswa mengamati kerja tim ahli, dalam hal ini adalah tim pengabdian Universitas Serang Raya yang selanjutnya disebut fasilitator dalam membuat produk sabun rumah tangga, strategi pemasaran dan perhitungan keuntungan.

2. Coaching, siswa dibina dan dibimbing fasilitator untuk melakukan kegiatan produksi dan manajemen usaha.

3. Scaffolding, siswa diberi kesempatan untuk melakukan kegiatan mandiri dengan bantuan fasilitator yang perlahan berkurang. 


\section{PEMBAHASAN}

Kegiatan pemagangan siswa SMKN 5 dan SMKS 17 Kota Serang dilakukan ke dalam tiga tahapan metode apprenticeship. Berikut uraian kegiatan di masing-masing tahapan.

\section{Modeling}

Pada tahap pertama yang dilakukan fasilitator adalah menjelaskan gambaran umum dan bahan-bahan yang digunakan dalam membuat produk sabun rumah tangga terdiri atas sabun mandi cair (liquid body wash), sabun cuci piring (liquid dish soap), dan sabun pembersih lantai (liquid floor cleaner). Selanjutnya fasilitator menunjukkan proses pembuatan sabun rumah tangga secara bertahap mulai dari bagaimana menakar ukuran bahan-bahan, proses mencampur bahan sampai menghasilkan produk yang siap digunakan. Adapun setelah sabun rumah tangga berhasil dibuat, fasilitator memaparkan strategi pemasaran dan peluang usaha produk berikut tata cara perhitungan keuntungan.
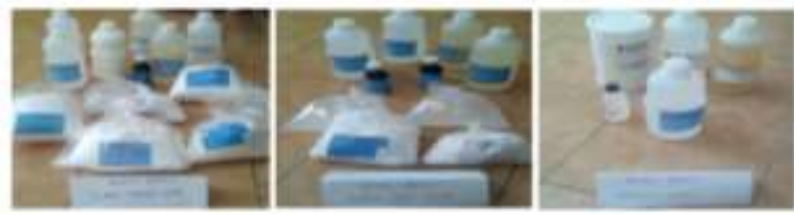

Gambar 1. Bahan-bahan Sabun Rumah Tangga

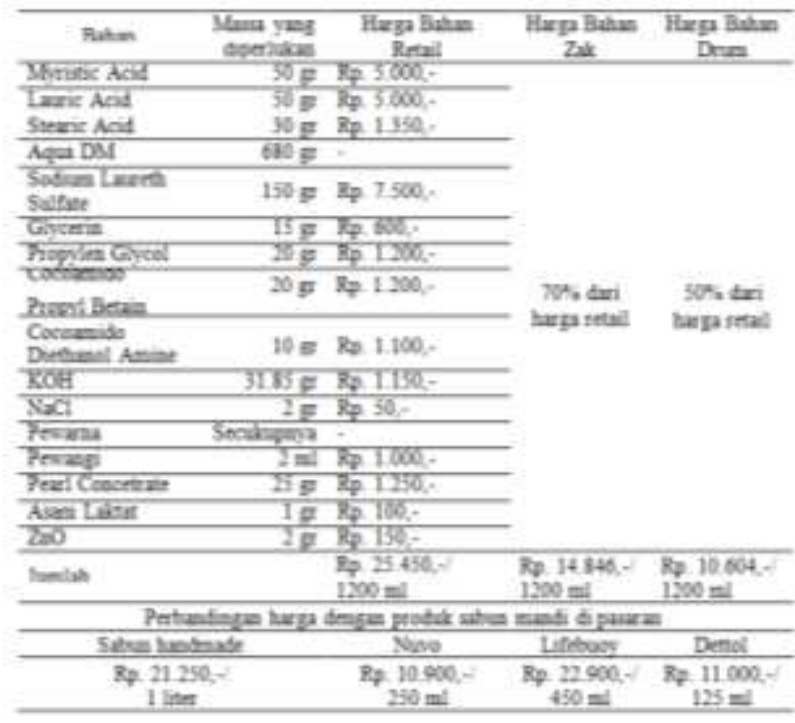

Gambar 2. Perhitungan Usaha Produk Sabun Mandi Cair oleh Tim Ahli di Tahap Modeling

\section{Coaching}

Pada tahap kedua, fasilitator meminta siswa untuk melakukan kegiatan membuat sabun rumah tangga di bawah binaan dan bimbingan penuh fasilitator. Selanjutnya menghitung modal yang dikeluarkan untuk membuat sabun dan harga jual yang layak untuk dipasarkan.

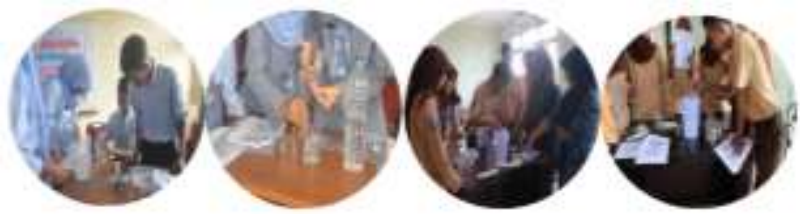

Gambar 3. Proses Pembuatan Sabun oleh Siswa

\begin{tabular}{|c|c|c|c|c|c|}
\hline \multicolumn{3}{|c|}{ Suban Cuá Prias } & \multicolumn{3}{|c|}{ Saben Pentest Lantu } \\
\hline Buban & $\begin{array}{l}\text { Matu youts } \\
\text { dipedulas }\end{array}$ & Harga & Bilan & $\begin{array}{l}\text { Manut yatid } \\
\text { dipetulane }\end{array}$ & Hurza \\
\hline $\begin{array}{l}\text { Toupin } \\
\text { air }\end{array}$ & $100 \mathrm{Fr}$ & Rp. 5.000 ; & Natansel & $11 \mathrm{er}$ & 70.2750 , \\
\hline S.OH & IE & Re. 150 & Tergad & 700 & $\mathrm{~kg} 750^{\circ}$ \\
\hline $\begin{array}{l}\text { Cocouseido } \\
\text { Dimtumnl } \\
\text { Amine }\end{array}$ & $30 \mathrm{cF}$ & Rp. 2.290,- & $\begin{array}{l}\text { Bennal } \\
\text { Kentium } \\
\text { Chlocide }\end{array}$ & $3=$ & Itp. 300 , \\
\hline $\begin{array}{l}\text { Cocakanide } \\
\text { Phogyi } \\
\text { Betrin }\end{array}$ & \multicolumn{2}{|c|}{$30 \mathrm{gr} \quad \mathrm{Rq} .1800$} & Twean 80 & \multicolumn{2}{|c|}{$5 \mathrm{~g} 3 \mathrm{3p} 650$} \\
\hline $\mathrm{Xac}$ & \multicolumn{2}{|c|}{ Ie 8925} & Pewas & \multicolumn{2}{|c|}{$I \equiv 1 R_{p} .656$} \\
\hline Afir & & Pesiena & \multicolumn{2}{|c|}{ Seculogeryz-1 } \\
\hline Penema & \multicolumn{2}{|l|}{ Secthrugy } & A $=$ & \multicolumn{2}{|c|}{$970 \mathrm{~m}-$} \\
\hline Penules & \multicolumn{2}{|c|}{$1 \mathrm{nd} \mathrm{R}$} & \multirow{2}{*}{\multicolumn{2}{|c|}{ Jumlah }} & \multirow{2}{*}{$\begin{array}{l}\text { Re } 5.100 \\
1100 \mathrm{mi}\end{array}$} \\
\hline Jumblak & & $\begin{array}{l}\text { Ro, } 9675,- \\
\text { II } 90 \mathrm{ml}\end{array}$ & & & \\
\hline \multicolumn{3}{|c|}{ 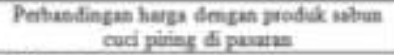 } & \multicolumn{3}{|c|}{$\begin{array}{l}\text { Petandingan hares dengan jroduk wbis } \\
\text { penberil latai di pasuras }\end{array}$} \\
\hline $\begin{array}{l}\text { Sulnum con } \\
\text { puriase } \\
\text { hundmade }\end{array}$ & $\begin{array}{l}\text { Manu } \\
\text { Lenosen }\end{array}$ & Sualigta & $\begin{array}{l}\text { Satrue tautal } \\
\text { habdmade }\end{array}$ & Supes Pell & $\begin{array}{l}\text { Sabe Lanta } \\
\text { mentk } \\
\text { Alfiman }\end{array}$ \\
\hline $\begin{array}{l}\text { Re: } 1+13 \text { : } \\
\text { it alite }\end{array}$ & $\begin{array}{c}\text { Re } 10300 \% \\
300 \mathrm{ml}\end{array}$ & $\begin{array}{c}R+13.500, c \\
600=1\end{array}$ & $\begin{array}{l}\text { Ra }+636,-2 \\
1 \text { line }\end{array}$ & $\begin{array}{c}\text { Ro } 11000, \\
500=1\end{array}$ & $\begin{array}{l}\mathrm{Rs}, 5500 \mathrm{C} \\
500 \mathrm{~mL}\end{array}$ \\
\hline
\end{tabular}

Gambar 4. Perhitungan Usaha Produk oleh Siswa di Tahap Coaching

\section{Scaffolding}

Di tahap ini, fasilitator memberikan siswa kesempatan untuk bereksperimen dan menguji pengalamannya secara mandiri dalam membuat sabun rumah tangga yang sesuai dengan takaran dan kreatifitas siswa. Sementara fasilitator menjadi pemantau dengan mengurangi frekuensi bantuan.

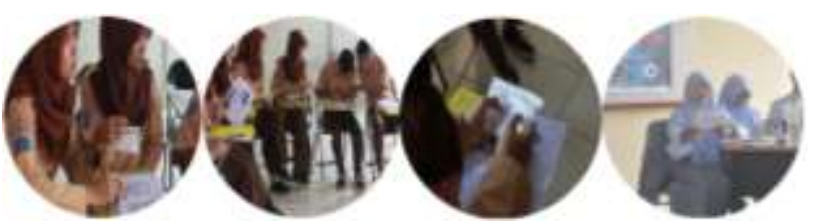

Gambar 5. Kegiatan Mandiri Siswa

Kegiatan pengabdian ditutup dengan
evaluasi melalui penjaringan angket untuk mengetahui persentase pemahaman siswa terhadap materi kegiatan. Data pada Tabel 1 memperlihatkan rata-rata pemahaman siswa dalam kegiatan apprenticeship mengenai peluang usaha dan tata kelola keuangan untuk memahamkan dan meningkatkan literasi finansial siswa SMK cukup baik yaitu 62,5\%. Nilai tersebut memberikan indikasi positif bahwa kegiatan pengabdian ini memberikan dampak yang baik sebagai permulaan untuk membangun motivasi 
dalam memulai atau membuka usaha. Hasil kegiatan ini menjadi bahan refleksi dan pertimbangan tim pengabdian Universitas Serang Raya dan pihak sekolah untuk bekerjasama menyelenggarakan kegiatan lanjutan dan berkesinambungan.

Tabel 1. Persentase Hasil Angket Pemahaman

\begin{tabular}{|c|c|c|}
\hline \multirow{2}{*}{ Aspek yang Diamati } & \multicolumn{2}{|c|}{ Pilihan Jawaban } \\
\hline & $\mathrm{Ya}$ & Tidak \\
\hline $\begin{array}{l}\text { Saya mengerti dengan } \\
\text { penjelasan fasilitator } \\
\text { tentang gambaran umum } \\
\text { bahan pembuatan } \\
\text { produk, tahapan proses } \\
\text { pembuatan sabun, } \\
\text { paparan strategi peluang } \\
\text { usaha dan tata cara } \\
\text { perhitungan keuntungan. }\end{array}$ & $75 \%$ & $25 \%$ \\
\hline $\begin{array}{l}\text { Pemahaman saya } \\
\text { terhadap pembuatan } \\
\text { sabun dan perhitungan } \\
\text { modal usaha semakin } \\
\text { berkembang sehingga } \\
\text { memberi dampak positif } \\
\text { pada kemampuan literasi } \\
\text { finansial. }\end{array}$ & $65 \%$ & $35 \%$ \\
\hline $\begin{array}{l}\text { Binaan dan bimbingan } \\
\text { fasilitator dalam proses } \\
\text { pembuatan produk dan } \\
\text { paparan tata kelola } \\
\text { modal usaha memotivasi } \\
\text { saya untuk membuka } \\
\text { peluang bisnis. }\end{array}$ & $65 \%$ & $35 \%$ \\
\hline $\begin{array}{l}\text { Inisiasi bisnis dan } \\
\text { keterampilan saya } \\
\text { mengatur modal usaha } \\
\text { dan menghitung laba } \\
\text { terasah melalui } \\
\text { bimbingan berjenjang } \\
\text { yang fasilitator berikan. }\end{array}$ & $55 \%$ & $45 \%$ \\
\hline $\begin{array}{l}\text { Saya melihat bahwa } \\
\text { tahapan kegiatan yang } \\
\text { ditunjukkan fasilitator } \\
\text { memiliki kesulitan } \\
\text { bertahap. }\end{array}$ & $60 \%$ & $40 \%$ \\
\hline $\begin{array}{l}\text { Rasa tertantang bebas } \\
\text { finansial di usia muda dan } \\
\text { jiwa kemandirian saya } \\
\text { terasah dalam mengikuti } \\
\text { kegiatan ketika fasilitator } \\
\text { semakin mengurangi } \\
\text { petunjuk dan bantuan. }\end{array}$ & $55 \%$ & $45 \%$ \\
\hline Rata-rata & $62.5 \%$ & $37,5 \%$ \\
\hline
\end{tabular}

\section{KESIMPULAN}

Kegiatan pengabdian untuk pelatihan usaha dan tata kelola keuangan sebagai upaya memahamkan dan meningkatkan literasi finansial siswa SMK melalui pembuatan sabun rumah tangga dengan metode apprenticeship menghasilkan pemahaman sebesar $62,5 \%$. Rata-rata presentase pemahaman siswa terbesar berada pada tahap kegiatan modeling dimana siswa mengamati dan melakukan kegiatan langsung dengan tim ahli atau fasilitator. Kegiatan ini diharapkan menjadi momentum terbentuknya semangat berinovasi dan literasi finansial generasi muda.

\section{PUSTAKA}

Badan Pusat Statistik Provinsi Banten, 2017, Keadaan Ketenagakerjaan Banten Agustus 2017, BPS Provinsi Banten, Serang.

Cave, A., 2010, Learning Math in Second Grade: An Application of Cognitive Apprenticeship. National Forum of Applied Educational Research Journal, 23 (3), 1-16.

Collins, A., Brown, J. S., dan Holum, A., 1991, Cognitive Apprenticeship: Making Thinking Visible. The Quartely Journal of The American Foundation of Teachers, Winter 1991, Issue American Educator.

Departemen Pendidikan Nasional Republik Indonesia, 2006, Undang-undang Republik Indonesia Nomor 20 Tahun 2003 tentang Sistem Pendidikan Nasional, Depdiknas, Jakarta.

Horn, D., 2014, The Effectiveness of Apprenticeship Training.,Budapest: Department of Human Resources, Cornivus Universitty of Budapest.

Idialu, E. E., 2013, Ensuring Quality Assurance in Vocational Education, Contemporary Issues In Education Research, 6 (4), 431-438.

Jones, A., 2018, Vocational Education for the Twenty-first Century, (Online), (https://melbournecshe.unimelb.edu.au/_data/assets/pdf_file/0011/2845 775/Final-Anne-Jones-paper1.pdf, Diakses 1 November 2018).

Kantor Perwakilan Bank Indonesia Provinsi Banten, 2018 Kajian Ekonomi dan Keuangan Regional Provinsi Banten Agustus 2018, BI Provinsi Banten, Serang.

Kersh, N., dan Juul, I., 2015, Vocational Education and Training as a Career Path for Young People: Making Choices in England and Denmark, (Online), (https://www.llakes.ac.uk/sites/default/files/52.\%20Kers h\%20and\%20Juul.pdf, Diakses 1 November 2018).

Pendidikan Menengah Kejuruan, 2008, Kurikulum SMK, Dikmenjur, Jakarta.

Oktaviyanthi, R., Djamal, N., dan Agus, R. N., 2015, Mengembangkan Livelihood Skills Siswa SMK Melalvi Pelatihan Saponify Handmade Soap Entrepreneurial di Kota Serang, (Online), (https://osf.io/preprints/weqsf/, Diakses 1 November 2018).

Toth, P., 2012, Learning Strategies and Styles in Vocational Education, Acta Polytechnica Hungarica, 9 (3), 195216.

Xu, L., dan Zia, B., 2012, Financial Literacy Around the World

(Online), (http://documents.worldbank.org/curated/en/2640014 
Rina Oktaviyanthi dkk, Sembadha 2018

68340889422/pdf/WPS6107.pdf, Diakses 1 November 2018). 